\title{
Statistical study regarding the identification of premature occlusal contacts in patients with Angle class I and class II malocclusions
}

\author{
Studiu statistic privind identificarea contactelor ocluzale premature la \\ pacienţii cu anomalii dento-maxilare clasa I şi clasa a II-a Angle
}

\section{Sergiu-Alexandru Rădulescu, Ecaterina Ionescu}

\section{Disciplina de Ortodonţie şi Ortopedie Dento-Facială, Facultatea de Medicină Dentară,} Universitatea de Medicină şi Farmacie „Carol Davila“, Bucureşti, România

\begin{abstract}
Objective. In this study we tried to identify the premature occlusal contacts that are present in patients with Angle Class I and Class II malocclusions.

Materials and method. For this study 60 patients with Angle Class I and Class II malocclusions were examined. Identification of premature occlusal contacts was made both clinically and with the help of study casts mounted in an adjustable articulator.

Results and discussion. Based on the statistical analysis made in this study we noticed that for patients with Angle Class I malocclusion, premature occlusal contacts from protrusion on the working side are more common, they are present in 15 patients, than to those with Angle Class II malocclusion where they were identified in 13 patients. In right laterotrusive edge to edge position we noticed that there are premature occlusal contacts on the working side in $43.3 \%$ of patients with Angle Class I malocclusion, and $50 \%$ of patients with Angle Class II malocclusion. Conclusions. In protrusive and laterotrusive edge to edge position there are premature occlusal contacts both at Angle Class I malocclusion, and in Angle Class II malocclusion patients. For practical conclusions, it is necessary to carry out more studies on the identification of occlusal premature contacts, which may occur in people with malocclusion.
\end{abstract}

Keywords: premature occlusal contacts, protrusion, laterotrusion

\section{REZUMAT}

Obiectiv. În studiul de faţă am încercat să identificăm contactele ocluzale premature care apar la pacienţii cu anomalii dento-maxilare Clasa I şi Clasa a II-a Angle.

Materiale şi metodă. Pentru realizarea acestui studiu au fost examinaţi 60 de pacienţi cu anomalii dentomaxilare Clasa I şi Clasa a II-a Angle. Identificarea contactelor ocluzale premature s-a realizat atât clinic, cât şi cu ajutorul modelelor de studiu montate într-un articulator adaptabil.

Rezultate şi discuţii. În urma analizei statistice realizate în cadrul acestui studiu am observat că la pacienţii cu anomalie dento-maxilară Clasa I Angle contactele ocluzale premature în propulsie pe partea lucrătoare sunt mai frecvente, apar la 15 pacienţi, decât la cei cu anomalie dento-maxilară Clasa a II-a Angle, unde au fost identificate în cazul a 13 pacienţi. În poziţia de cap la cap în lateralitate dreapta am observat că există contacte ocluzale premature pe partea lucrătoare la $46,3 \%$ dintre pacienţii cu anomalie dento-maxilară Clasa I Angle şi la $50 \%$ dintre pacienţii cu anomalie dento-maxilară Clasa a II-a Angle.

Concluzii. În poziţiile de cap la cap în propulsie şi lateralitate există contacte premature atât la pacienţii cu anomalie dento-maxilară Clasa I Angle, cât şi la cei cu anomalie dento-maxilară Clasa a II-a Angle. Pentru concluzii cu aplicabilitate practică este necesar să se realizeze mai multe studii cu privire la identificarea contactelor ocluzale premature în propulsie şi lateralitate, care pot apărea în cazul persoanelor cu anomalii dentomaxilare. 


\section{INTRODUCERE}

În timpul funcției masticatorii, mandibula ajunge, în anumite momente, în pozițiile de cap la cap în propulsie şi lateralitate dreapta respectiv stânga, iar aceste poziții trebuie să fie susținute de cât mai mulţi dinţi pentru ca aceştia să nu fie suprasolicitaţi de forțele ocluzale. În cazul poziției de cap la cap în propulsie, această poziție ar trebui să fie susținută de minimum doi incisivi maxilari şi antagoniştii lor, iar dinții din zona laterală (parte nelucrătoare) nu ar trebui să fie în contact. Atunci când în această poziție apar contacte între dinții din zona laterală, acestea se numesc contacte ocluzale premature în propulsie pe partea nelucrătoare, fiind nocive deoarece forțele ocluzale se transmit în afara axului lung al dinților în cauză. La finalul mișcărilor de lateralitate spre dreapta şi spre stânga, dinţii de pe partea spre care se realizează mişcarea de lateralitate ajung în poziția de cap la cap (zonă lucrătoare). Această poziție ar trebui să fie susținută fie de canini, de toți dinții laterali şi canini, de toți dinții laterali sau de canini şi 2-3 dinţi laterali succesivi, orice alte contacte ocluzale care susțin această poziție fiind considerate contacte ocluzale premature în lateralitate pe partea lucrătoare. În poziția de cap la cap în lateralitate pe partea spre care s-a realizat mişcarea, dinții de pe hemiarcadele opuse (zonă nelucrătoare) nu ar trebui să fie în contact pentru a nu fi suprasolicitați. Orice contact între dinții de la nivelul zonei nelucrătoare se numesc contacte ocluzale premature în lateralitate pe partea nelucrătoare (1).

Acest studiu are ca scop identificarea contactelor ocluzale premature care pot să apară la finalul mişcărilor de propulsie şi lateralitate, la pacienții cu anomalii dento-maxilare Clasa I şi Clasa a II-a Angle, care nu au beneficiat de tratament ortodontic.

\section{MATERIALE ŞI METODĂ}

Studiul a fost realizat în urma examinării clinice a 60 de pacienţi cu vârsta cuprinsă între 16 şi 26 ani - 27 de sex feminin şi 33 de sex masculin -, înainte de a începe tratamentul ortodontic. Pacienții au fost grupați în două loturi de studiu, în funcție de diagnosticul de malocluzie, astfel: 30 de pacienți cu malocluzie clasa I Angle şi 30 de pacienţi cu malocluzie clasa a II-a Angle. Criteriile de includere în studiu au fost următoarele: dentiție permanentă, ab- sența edentațiilor, absența lucrărilor protetice şi lipsa tratamentului ortodontic în antecedente.

Identificarea contactelor ocluzale premature ce apar în pozițiile de cap la cap în propulsie şi lateralitate a fost realizată clinic şi cu ajutorul modelelor de studiu montate în articulator. Am informat fiecare participant la studiu în legătură cu manoperele pe care le voi realiza şi le-am prezentat instrumentele şi materialele folosite. Pentru identificarea clinică a contactelor ocluzale premature din poziţia de cap la cap în propulsie, am rugat pe fiecare pacient să efectueze mişcarea de propulsie pornind din poziția de intercuspidare maximă. După ce dinții din zona frontală (zonă lucrătoare) au ajuns în poziția de cap la cap, i-am notat pe cei care mențin această poziție şi am examinat şi dinții din zona laterală (zonă nelucrătoare) pentru a-i identifica pe cei care au contact. În continuare, am înregistrat poziția de cap la cap în propulsie, folosind ceară preformată de înregistrare a ocluziei. Ceara a fost plastifiată în apă caldă şi introdusă în cavitatea bucală pe suprafața ocluzală a dinților maxilari, fiind decupată în zona frontală şi acoperind în totalitate suprafețele ocluzale ale dinților din zona laterală. Pacientul a fost rugat să efectueze mişcarea de propulsie până în poziția de cap la cap şi în această poziţie să ocludă uşor pe folia de ceară pentru a rămâne imprimate vârfurile cuspizilor dinților din zona laterală.

În vederea identificării contactelor ocluzale premature din poziția de cap la cap în lateralitate dreapta, am condus mandibula fiecărui pacient în această poziție pornind din poziția de intercuspidare maximă şi am notat atât dinții care vin în contact pe partea dreaptă (zonă lucrătoare) cât şi pe cei din partea stângă (zonă nelucrătoare). În continuare, am înregistrat poziția de cap la cap în lateralitate dreapta, folosind ceară preformată de înregistrare a ocluziei. Ceara a fost plastifiată în apă caldă şi introdusă în cavitatea bucală pe suprafața ocluzală a dinților maxilari, acoperind în totalitate suprafețele ocluzale ale acestora. Am ghidat mandibula pacientului în lateralitate spre dreapta, până în poziția de cap la cap şi în această poziție 1-am rugat să ocludă uşor pe folia de ceară pentru a rămâne imprimate vârfurile cuspizilor dinților din zona laterală. Aceleaşi manopere le-am realizat şi pentru identificarea contactelor premature din poziția de cap la cap în lateralitate stânga. Pentru fiecare pacient am avut modelele de studiu montate într-un articulator 
adaptabil la nivelul căruia am programat înclinarea pantei articulare, unghiurile şi mişcările Bennett cu ajutorul înregistrărilor interocluzale ale pozițiilor de cap la cap în propulsie şi lateralitate.

\section{REZULTATE}

Datele colectate au fost introduse într-un computer şi analizate folosind programul de analiză statistică IBM SPSS versiunea 13.0, iar tabelele au fost realizate cu programul Microsoft Excel 2013. După ce am realizat testul de normalitate ShapiroWilk, am calculat frevența şi procentul contactelor ocluzale premature care apar la nivelul zonelor lucrătoare şi nelucrătoare. Prin urmare, rezultatele obținute sunt prezentate în cele ce urmează.

Contactele ocluzale premature în propulsie pe partea lucrătoare au fost identificate la 50\% (15 cazuri) dintre pacienții cu anomalie dento-maxilară clasa I Angle şi au fost absente la restul de 50\% (15 cazuri). La pacienții cu anomalie dento-maxilară clasa a II-a Angle, acest tip de contacte ocluzale premature a fost prezent la 43,3\% (13 cazuri) dintre aceştia şi absent la 56,7\% (17 cazuri) dintre subiecți (Fig. 1).

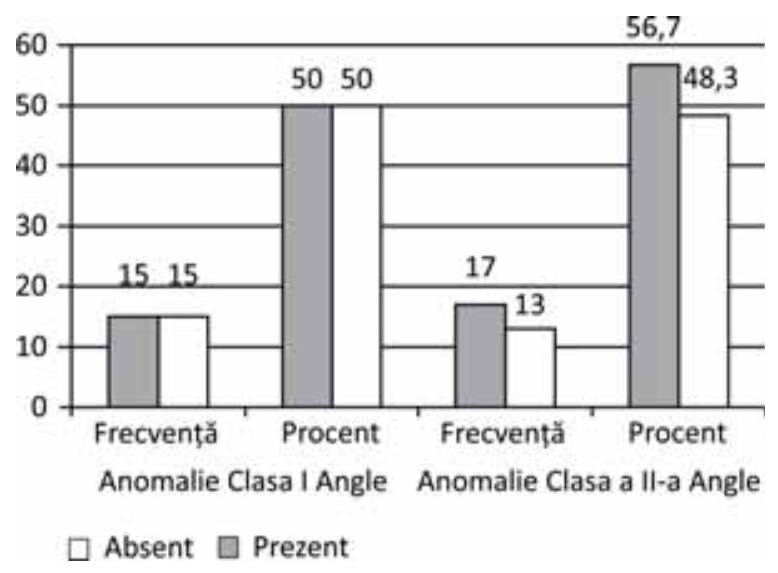

FIGURA 1. Contacte ocluzale premature în propulsie pe partea lucrătoare

Contactele ocluzale premature în propulsie pe partea nelucrătoare au fost prezente la 13,3\% (4 cazuri) dintre pacienții cu anomalie dento-maxilară clasa I Angle şi absente la 86,7\% (26 cazuri) dintre aceştia. La pacienții cu anomalie dento-maxilară clasa a II-a Angle acest tip de contacte ocluzale premature a fost prezent la 30\% (9 cazuri) dintre aceştia şi absent la 70\% (21 cazuri) dintre subiecți (Fig. 2).

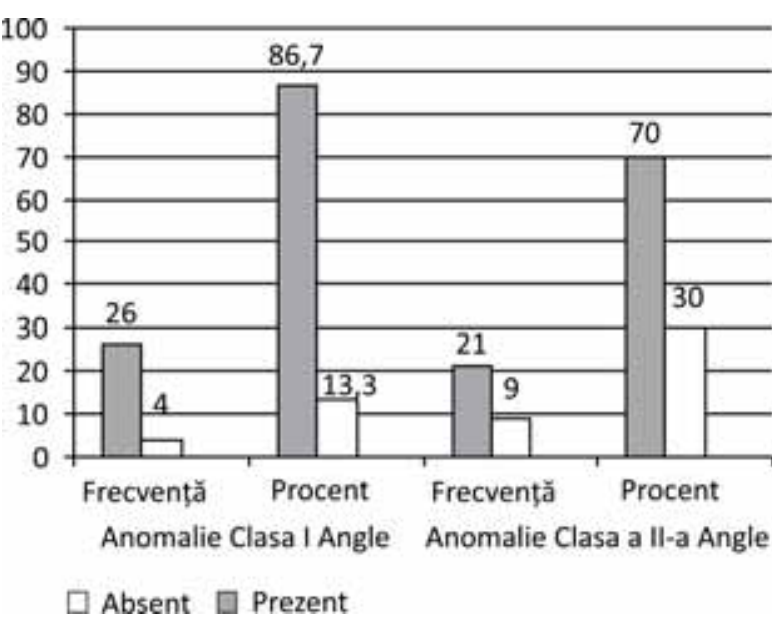

FIGURA 2. Contacte ocluzale premature în propulsie pe partea nelucrătoare

Contactele ocluzale premature în lateralitate spre dreapta pe partea lucrătoare au fost prezente la 43,3\% (13 cazuri) dintre pacientii cu anomalie dento-maxilară clasa I Angle şi absente la 56,7\% (17 cazuri) dintre aceştia. La pacienții cu anomalie dento-maxilară clasa a II-a Angle, acest tip de contacte ocluzale premature a fost prezent la 50\% (15 cazuri) dintre aceştia şi absent la 50\% (15 cazuri) dintre subiecți (Fig. 3).

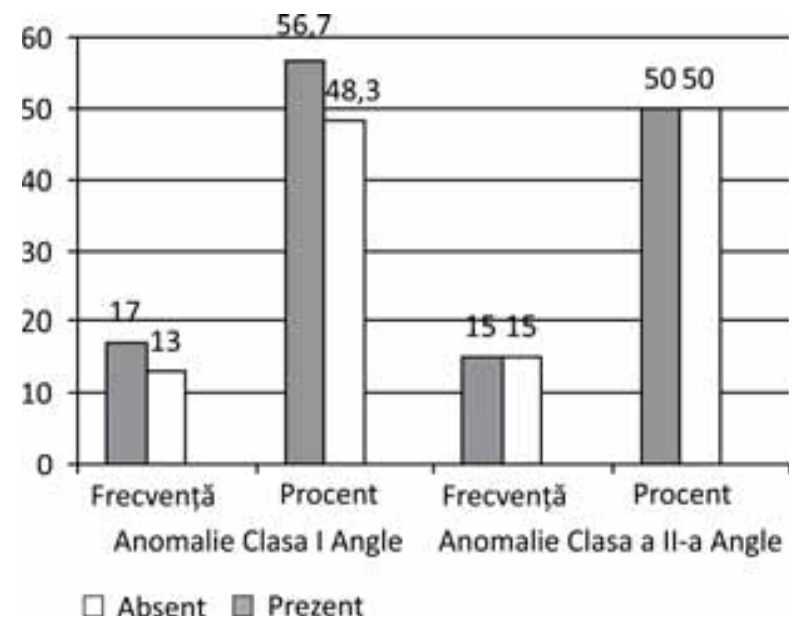

FIGURA 3. Contacte ocluzale premature în lateralitate spre dreapta pe partea lucrătoare

Contactele ocluzale premature în lateralitate spre dreapta pe partea nelucrătoare au fost prezente la 30\% (9 cazuri) dintre pacienții cu anomalie dento-maxilară clasa I Angle şi absente la 70\% (21 cazuri) dintre aceştia. Acelaşi tip de contacte ocluzale premature a fost prezent la $26,7 \%$ (8 cazuri) dintre pacienții cu anomalie dento-maxilară clasa a II-a Angle şi absent la 73,3\% (22 cazuri) dintre aceştia (Fig. 4). 


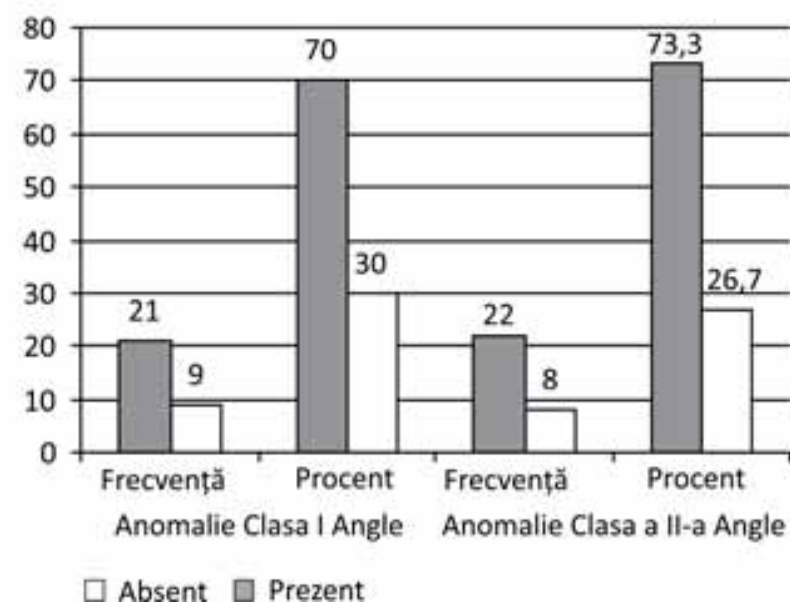

FIGURA 4. Contacte ocluzale premature în lateralitate spre dreapta pe partea nelucrătoare

Contactele ocluzale premature în lateralitate spre stânga pe partea lucrătoare au fost prezente la 56,7\% (17 cazuri) dintre pacienții cu anomalie dento-maxilară clasa I Angle şi absente la 43,3\% (13 cazuri) dintre aceştia. În cazul pacienților cu anomalie dento-maxilară clasa a II-a Angle, acest tip de contacte ocluzale premature a fost prezent la $30 \%$ (9 cazuri) şi absent la 70\% (21 cazuri) dintre aceştia (Fig. 5).

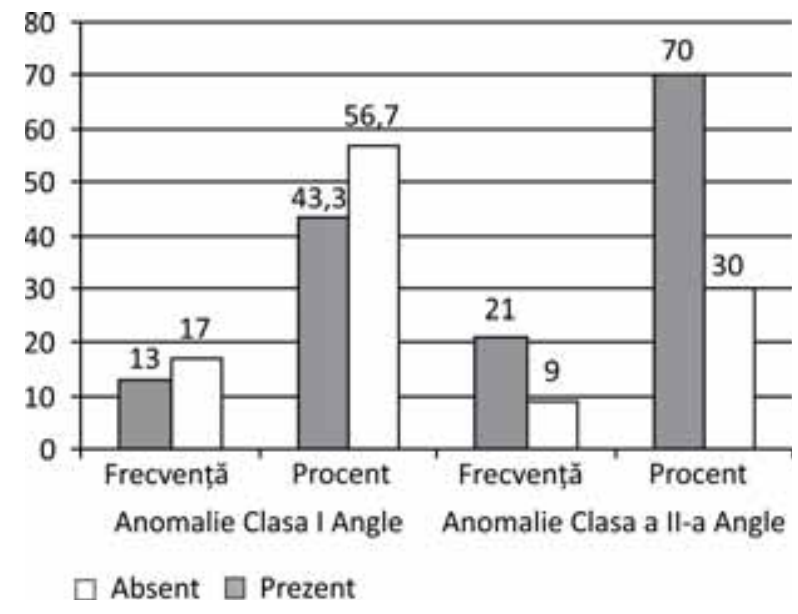

FIGURA 5. Contacte ocluzale premature în lateralitate spre stânga pe partea lucrătoare

Contactele ocluzale premature în lateralitate spre stânga pe partea nelucrătoare au fost identificate la $16,7 \%$ (5 cazuri) dintre pacienții cu anomalie dento-maxilară clasa I Angle şi absente la 83,3\% (25 cazuri) dintre aceştia. La pacienții cu anomalie dento-maxilară clasa a II-a Angle, acest tip de contacte ocluzale premature a fost prezent la 36,7\% (11 cazuri) şi absent la 63,3\% (19 cazuri) dintre aceştia (Fig. 6).

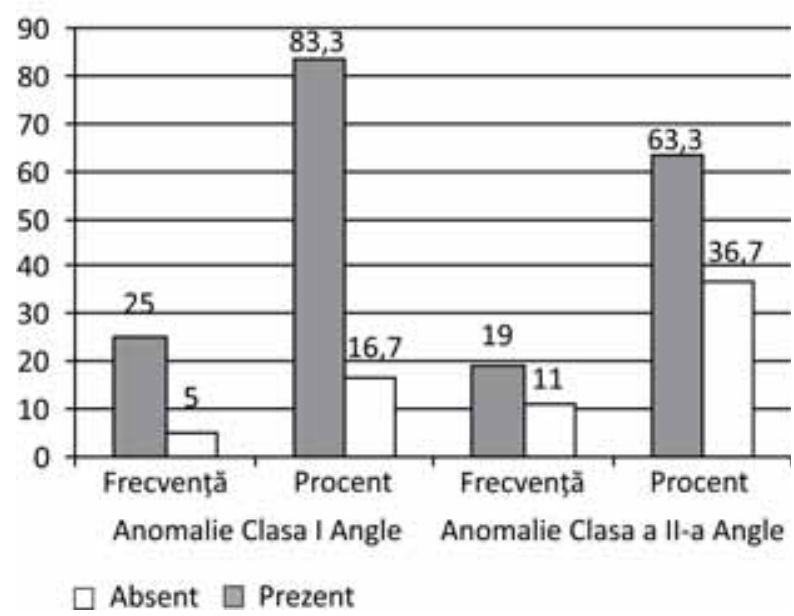

FIGURA 6. Contacte ocluzale premature în lateralitate spre stânga pe partea nelucrătoare

\section{DISCUṬII}

În urma analizei statistice realizate în cadrul acestui studiu am observat că la pacienții cu anomalie dento-maxilară Clasa I Angle contactele ocluzale premature în propulsie pe partea lucrătoare sunt mai frecvente, apar la 15 pacienți, decât la cei cu anomalie dento-maxilară Clasa a II-a Angle unde au fost identificate în cazul a 13 pacienți. Rinchuse şi Sassouni într-un studiu realizat pe 76 de pacienți au găsit contacte ocluzale premature în propulsie pe partea lucrătoare la 24 dintre pacienții examinați (2).

În ceea ce priveşte contactele ocluzale premature din propulsie pe partea nelucrătoare, am observat că sunt prezente la 13,3\% dintre pacienții cu anomalie dento-maxilară Clasa I Angle şi la 30\% dintre pacienții cu anomalie dento-maxilară Clasa a II-a Angle.

În poziția de cap la cap în lateralitate dreapta am observat că există contacte ocluzale premature pe partea lucrătoare la 46,3\% dintre pacienții cu anomalie dento-maxilară Clasa I Angle şi la 50\% dintre pacienții cu anomalie dento-maxilară Clasa a II-a Angle. În aceeaşi poziţie, contactele ocluzale premature de pe partea nelucrătoare au fost identificate la $30 \%$ dintre pacienții cu anomalie dentomaxilară Clasa I Angle şi la 25,7\% dintre cei cu anomalie dento-maxilară Clasa a II-a Angle.

Referitor la contactele ocluzale premature din poziția de cap la cap în lateralitate stânga, am observat că, pe partea lucrătoare, acestea apar la 56,7\% dintre pacienții cu anomalie dento-maxilară Clasa I Angle, pe când la pacienții cu anomalie dento- 
maxilară clasa a II-a Angle sunt prezente la 30\% dintre aceştia. Pe partea nelucrătoare, cele mai multe contacte ocluzale premature se întâlnesc la pacienții cu anomalie dento-maxilară Clasa a II-a Angle şi cele mai puține la cei cu anomalie dento-maxilară Clasa I Angle, fiind prezente la 36,7\% respectiv $15,7 \%$ dintre pacienți.

Ahlgren şi Posselt, Cohen, Gazit şi Lieberman, precum şi Sadowsky şi BeGole în studiile realizate de fiecare, ce însumează un număr total de 410 pacienți care nu au beneficiat de tratament ortodontic, au observat că majoritatea pacienților examinaţi prezintă contacte ocluzale premature în lateralitate pe partea nelucrătoare $(3,4)$. Un studiu realizat de Ingerval pe 50 de adulți arată că există contacte premature pe partea nelucrătoare în cazul celor două poziții de cap la cap în lateralitate dreapta, respectiv stânga la $84 \%$ dintre pacienții examinați (5). Într-un studiu realizat de Weinberg, majoritatea subiecților au prezentat contacte ocluzale premature în lateralitate pe partea nelucrătoare. Pe de altă parte, D'arnico, Beiron, Ismail şi Guevara precum şi Scaife şi Holt nu au identificat prezența contactelor ocluzale premature în lateralitate pe partea nelucrătoare la pacienții pe care i-au examinat (6).

\section{CONCLUZII}

Analizând rezultatele acestui studiu, putem concluziona că în poziţiile de cap la cap în propulsie şi lateralitate există contacte premature atât la pacienții cu anomalie dento-maxilară Clasa I Angle, cât şi la cei cu anomalie dento-maxilară Clasa a II-a Angle, dar nu există diferențe semnificative între pacienții din cele două grupuri.

Aceste contacte ocluzale premature ar trebui să fie îndepărtate prin tratament ortodontic.

Pentru concluzii cu aplicabilitate practică este însă necesar să se realizeze mai multe studii cu privire la identificarea contactelor ocluzale premature în propulsie şi lateralitate, care pot apărea în cazul persoanelor cu anomalii dento-maxilare.

Conflict of interest: none declared Financial support: none declared

\section{$\overline{\text { BIBLIOGRAFIE }}$}

1. Alexandru P., Sergiu I., Petre A., Ioniță S. Ocluzia dentară. Noțiuni de morfologie, fiziologie, patologie şi tratament. Editura Didactică şi Pedagocică, R.A., Bucureşti, 2003

2. Rinchuse D.J., Sassouni V. An evaluation of functional occlusal interferences in orthodontically treated and untreated subjects. The Angle Orthodontist. April, 1983; 53(2):122-130

Ahlgren J., Posselt V. Need of functional analysis and selective grinding in orthodontics - a clinical and electromyographic study. Acta Odonto. 1963; Scand $21: 187-226$
3. Sadowsky C., BeGole E.A. Long term status of temporomandibular joint function and functional occlusion after orthodontic treatment. Am. J. Orthod. August; 1980 78(2):201-212,

4. Ingerval B. Tooth contacts on the functional and nonfunctional side in children and zoung adults. Archs Oral Biol. 1972; 17:191-200

Weinberg L.A. The prevalence of tooth contact in eccentric movements of the jaws: its clinical implications. J. Am. Dent. Assoc. 1961; 62:402-406 